\title{
Detection of left atrial thrombi by echocardiography
}

\author{
P SCHWEIZER, P BARDOS, R ERBEL, J MEYER, W MERX, B J MESSMER, \\ S EFFERT
}

From the Department of Internal Medicine I and Department of Cardiovascular Surgery, Rheinisch-Westfälische Technische Hochschule, Aachen, West Germany

SUMMARY A group of 111 patients with mitral valve disease was studied by M-mode and two-dimensional echocardiography. Five left atrial thrombi were demonstrated, two of which had probably been the source of previous embolic events.

Two-dimensional echocardiography was superior to M-mode in providing spatial orientation. Using multiple cross-sections the exact localisation and the size of the thrombus formation could be estimated. Thrombus localisations at the upper, lateral, and septal atrial walls, normally inaccessible to the single-beam technique, were successfully imaged.

Even two-dimensional echocardiography, however, constitutes an imperfect method. By comparison with the findings at surgery only one-third of confirmed thrombi could be detected non-invasively. According to their localisation seven clots in the appendage were missed by the ultrasound method. One further thrombus fixed to the upper left atrial wall near the entrance of the upper pulmonary veins was also undetected by echocardiography.

Despite these limitations, the information provided by echocardiography can be most helpful in patient management. $M$-mode, in combination with two-dimensional echocardiography, is therefore recommended in all patients with mitral stenosis before invasive diagnostic or therapeutic procedures are undertaken.

The mobilisation of a left atrial mass with production of systemic emboli is a rare but justly dreaded complication during invasive diagnostic or therapeutic procedures. ${ }^{1-3}$

M-mode echocardiography has now become an established non-invasive method for the early detection of myxomas prolapsing into the mitral orifice during diastole. ${ }^{4} 5$ But this method is supposed to be inadequate for the diagnosis of immobile masses, especially mural left atrial thrombi. ${ }^{7}$ The advent of two-dimensional echocardiography with its ability to provide spatial orientation seems to give better diagnostic perspectives.

This report describes experience with both M-mode and two-dimensional echocardiography in the detection of left atrial thrombi in mitral stenosis.

\section{Subjects and methods}

A total of 111 consecutive patients with significant mitral stenosis were studied who were referred to Received for publication 2 May 1980 the cardiovascular laboratory for catheterisation between August 1978 and November 1979. Besides clinical evaluation each patient underwent subtle $\mathrm{M}$-mode and two-dimensional echocardiographic examination before the invasive procedures.

\section{ECHOCARDIOGRAPHIC STUDIES}

M-mode echocardiographic studies were performed using an Organon ultrasonograph interfaced with a Honeywell 1856 strip chart recorder; $2 \cdot 25 \mathrm{MHz}$ transducers focused at 7.5 and $10 \mathrm{~cm}$ were used. These were recorded with the patient in the supine or $30^{\circ}$ left lateral decubitus position. The transducer was placed in the third, fourth, and fifth intercostal space at the left sternal border.

A complete $\mathrm{M}$-mode sector scan from the aorta and the left atrium towards the apex was performed. The transducer was then angled towards the right shoulder to get an optimal sweep of the left atrium. During this sweep gain control was adjusted to receive clear-cut echoes of the atrial borders.

Two-dimensional echocardiography was performed with a Varian V-3000 wide-angle, $84^{\circ}$, phased array sector scanner. Serial cross-sectional 
images through the long and short axis of the heart were recorded by placing the transducer at the left sternal border. These views allowed visualisation of the posterior and lateral atrial walls as well as of the mitral valve apparatus. ${ }^{8}$ The transducer was then placed at the cardiac apex impulse and from this position the four chamber apex view was obtained. This image plane allowed an additional identification of the septal parts of the left atrium and of the upper portions near the entrance of the inferior pulmonary veins. ${ }^{9} 10$

The cross-sectional images were permanently recorded on videotape for later playback. The illustrations presented in this article are $35 \mathrm{~mm}$ photographs of single-frame images from the videotape.

\section{CATHETERIZATION METHODS}

All patients underwent complete left and right heart catheterisation from the right groin using the Seldinger technique.

In older patients coronary angiography was performed using the Judkins technique.

In patients with the non-invasive diagnosis of an atrial thrombus the transseptal approach to the left atrium was avoided. The opacification of the left atrium was then obtained by injection of the contrast medium into the main pulmonary artery. Biplane cineangiograms were recorded on $35 \mathrm{~mm}$ film.
SURGICAL INTERVENTIONS

After catheterisation and angiography, 92 patients (28 men and 64 women) aged 29 to 72 years with a mean age of $53 \pm 8$ years had open heart surgery. The left atrium was thoroughly searched for mural thrombi to compare the morphological findings with those of echocardiography and angiography.

\section{Results}

In five of the 111 patients left atrial thrombi could be identified by $M$-mode and/or two-dimensional echocardiography before invasive procedures. The echocardiographic diagnosis was confirmed in all patients by cineangiography via the pulmonary artery. Four of these patients were operated on and the echocardiographic findings could thus be documented.

The clinical data for each patient are summarised in the Table. Four patients were in atrial fibrillation. Two patients had previous embolic events. One of the three patients with coexistent coronary artery disease could not be operated on because of the severity of this disease and low ejection fraction.

\section{M-MODE ECHOCARDIOGRAPHIC FINDINGS}

In three patients the standard M-mode echocardiograms disclosed thickened, layered echoes in front of the posterior left atrial wall (cases 1 to 3 ). These echoes were continuously visible during

Table Clinical data

\begin{tabular}{|c|c|c|c|c|c|c|c|c|}
\hline $\begin{array}{l}\text { Case } \\
\text { No. }\end{array}$ & $\begin{array}{l}\text { Age, } \\
(y)\end{array}$ & $\operatorname{sex}$ & $\begin{array}{l}\text { Underlying cardiac } \\
\text { disease }\end{array}$ & Embolic episodes & $\begin{array}{l}\text { M-mode } \\
\text { echocardiogram }\end{array}$ & $\begin{array}{l}\text { Two-dimensional } \\
\text { echocardiogram }\end{array}$ & $\begin{array}{l}\text { Pulmonary } \\
\text { cineangiogram }\end{array}$ & Surgical findings \\
\hline 1 & 57 & $\mathbf{F}$ & $\begin{array}{l}\text { Mitral stenosis and } \\
\text { regurgitation; } \\
\text { atrial fibrillation; } \\
\text { coronary artery } \\
\text { disease }\end{array}$ & 一 & $\begin{array}{l}\text { Diagnostic; } \\
\text { thickened echoes } \\
\text { in front of } \\
\text { posterior left } \\
\text { atrial wall }\end{array}$ & $\begin{array}{l}\text { Immobile mass } \\
\text { attached to } \\
\text { posterior, septal, } \\
\text { and upper left } \\
\text { atrial wall }\end{array}$ & Large filling defect & $\begin{array}{l}\text { Firmly organised } \\
\text { mass thrombus, } \\
\text { not calcified }\end{array}$ \\
\hline 2 & 64 & $\mathbf{F}$ & $\begin{array}{l}\text { Mitral stenosis; } \\
\text { aortic } \\
\text { regurgitation; } \\
\text { atrial fibrillation; } \\
\text { coronary artery } \\
\text { disease }\end{array}$ & - & $\begin{array}{l}\text { Diagnostic; } \\
\text { abnormal } \\
\text { echoes similar to } \\
\text { case } 1\end{array}$ & $\begin{array}{l}\text { Immobile mass } \\
\text { attached to } \\
\text { posterior, septal } \\
\text { lateral, and upper } \\
\text { left atrial wall }\end{array}$ & $\begin{array}{l}\text { Two large filling } \\
\text { defects }\end{array}$ & - \\
\hline 3 & 57 & $\mathbf{M}$ & $\begin{array}{l}\text { Mitral stenosis; } \\
\text { atrial fibrillation; } \\
\text { coronary artery } \\
\text { disease }\end{array}$ & Cerebral emboli & $\begin{array}{l}\text { Diagnostic; } \\
\text { abnormal echoes } \\
\text { similar to } \\
\text { case } 1\end{array}$ & $\begin{array}{l}\text { Immobile mass in } \\
\text { broad contact with } \\
\text { posterior, septal, } \\
\text { and upper left } \\
\text { atrial wall }\end{array}$ & Large filling defect & $\begin{array}{l}\text { Organised mass } \\
\text { thrombus; not } \\
\text { calcified }\end{array}$ \\
\hline 4 & 41 & $\mathbf{M}$ & $\begin{array}{l}\text { Mitral stenosis; } \\
\text { sinus rhythm }\end{array}$ & $\begin{array}{l}\text { Emboli to right } \\
\text { kidney }\end{array}$ & $\begin{array}{l}\text { Suggestive; } \\
\text { thrombus? } \\
\text { mitral valve ring } \\
\text { calcification? }\end{array}$ & $\begin{array}{l}\text { Echo-mass } \\
\text { attached to } \\
\text { posterior mitral } \\
\text { leaflet, moving } \\
\text { back and forth }\end{array}$ & $\begin{array}{l}\text { Calcified mass on } \\
\text { fluoroscopy; } \\
\text { filling defect }\end{array}$ & $\begin{array}{l}\text { Heavily calcified } \\
\text { thrombus }\end{array}$ \\
\hline 5 & 59 & $\mathbf{F}$ & $\begin{array}{l}\text { Mitral stenosis; } \\
\text { atrial fibrillation }\end{array}$ & - & $\begin{array}{l}\text { Not diagnostic; } \\
\text { echo-free left } \\
\text { atrium }\end{array}$ & $\begin{array}{l}\text { Immobile echo } \\
\text { mass fixed to } \\
\text { upper left atrial } \\
\text { wall }\end{array}$ & Filling defect & $\begin{array}{l}\text { Globular thrombus; } \\
\text { partly organised, } \\
\text { partly fresh } \\
\text { thrombotic } \\
\text { material }\end{array}$ \\
\hline
\end{tabular}


Fig. 1 M-mode echocardiographic sweep from the mitral valve region to the aorta and the left atrium in mitral stenosis. Dense parallel lines anterior to the posterior left atrial wall suggesting thrombus. The arrow marks the true borders of the left atrium without thrombus (case 2).

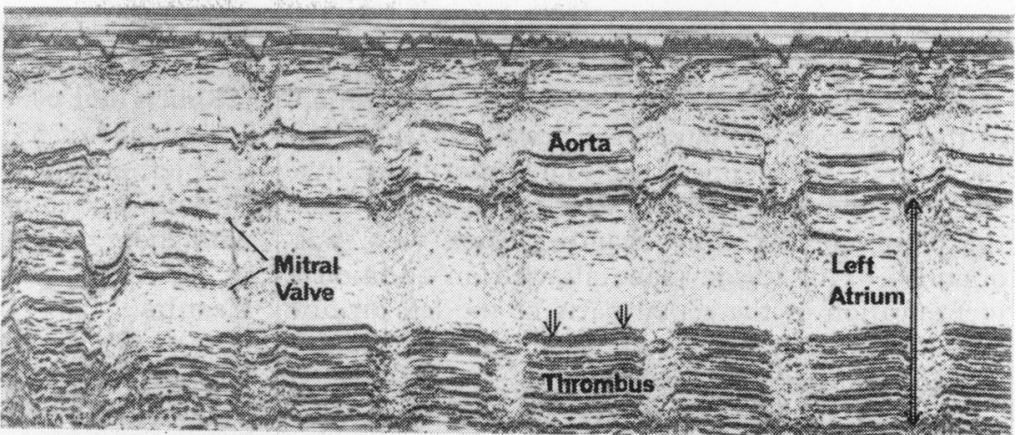

Case 2 systole and diastole. Because of the strength of these abnormal echoes, persisting at low recorder gain, the true left atrial wall was difficult to delimit. The diameter of the left atrium was therefore apparently small in relation to the degree of mitral stenosis (Fig. 1). In one patient (case 4) the M-mode echocardiogram was difficult to interpret. The strong echoes behind the posterior mitral leaflet were consistent with the diagnosis of mitral valve ring calcification as well as with that of a left atrial mass (Fig. 2).

In one further patient with a definite twodimensional echocardiographic diagnosis of a left atrial thrombus no clear-cut echoes within the left atrium could be documented by $\mathrm{M}$-mode echocardiography (case 5).

\section{TWO-DIMENSIONAL ECHOCARDIOGRAPHIC} FINDINGS

In five patients two-dimensional echocardiography showed the presence of a large mass of echoes within the left atrium. This mass suggesting thrombus could be localised and its size could be estimated using multiple cross-sections. In three patients this mass was immobile and in broad contact with the septal, lateral, posterior, and upper parts of the left atrial wall (cases 1 to 3; Fig. 3, 4). This thrombus formation, also situated near the mitral valve apparatus, had likewise been identified by $M$-mode echocardiography. In one patient the echo-dense mass was attached to the posterior mitral leaflet and moved back and forth during diastole and systole (Fig. 5). In case 5, a welldefined mass, deep within the left atrium and attached to the posterior and superior wall, was clearly demonstrated by two-dimensional echocardiography, but was not positively identified by M-mode echocardiography (Fig. 6).

\section{CINEANGIOGRAPHIC FINDINGS}

In all five patients cineangiography via the pulmonary artery disclosed filling defects within the

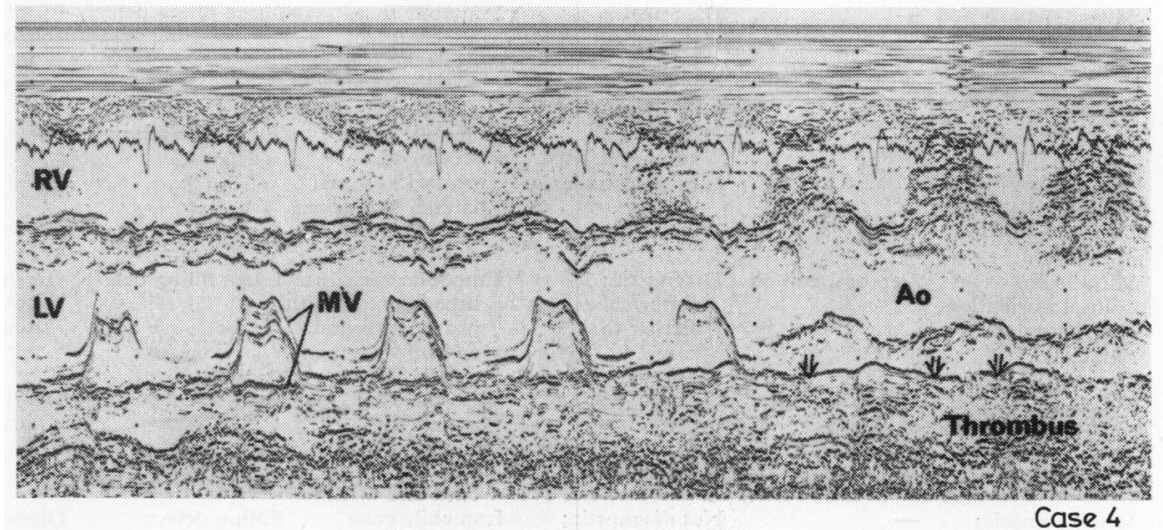

Fig. 2 M-mode scan for case 4 with mitral stenosis from the left ventricle (LV) to the aorta (Ao) and left atrium. Record of broad and continuous echo bands behind the posterior leaflet of the mitral valve (MV). The band extends into the left atrium suggesting mitral valve ring calcification or thrombus. 
left atrium (Fig. 7). The localisation of these findings was similar to that of two-dimensional echocardiography. In case 5 fluoroscopy already showed large calcification in the area of the mitral valve which moved during diastole and systole (Fig. 8).

\section{SURGICAL FINDINGS}

In all four patients who were operated on, the left atrium contained larger thrombotic masses. These were firmly organised and fibrotic in two patients and heavily calcified in one.

In case 5 the globular mass attached to the upper part of the left atrium near the entrance of the inferior pulmonary veins consisted of partly organised and partly fresh thrombotic material (Fig. 9). The localisation of the four thrombi correlated exactly with the preoperative twodimensional echocardiographic findings.

\section{THROMBI NOT DETECTED BY}

\section{ECHOCARDIOGRAPHY}

Cardiovascular surgery showed a further eight patients with mitral stenoses and left atrial thrombi, which were not detected by echocardiography during the follow-up period of 16 months. The age of these patients was between 45 and 63 years. (two men and six women). All patients were in atrial fibrillation and two had had previous embolic events.

One larger thrombus was attached to the upper part of the left atrium near the entrance of the superior pulmonary veins. Three further thrombi filled and protruded from the left atrial appendage and were also retrospectively identified by cineangiography. The other four thrombi were small, not larger than a pea, and only filled the tip of the atrial appendage.

\section{Discussion}

Until recently the only method available for the detection of left atrial thrombi has been cineangiography. ${ }^{11-15}$ Attempts to use M-mode echocardiography have been disappointing. Few published reports are to be found, all emphasising the diagnostic difficulties encountered with this method. ${ }^{6} 71617$

On the other hand, the usefulness of twodimensional echocardiography in the diagnosis of
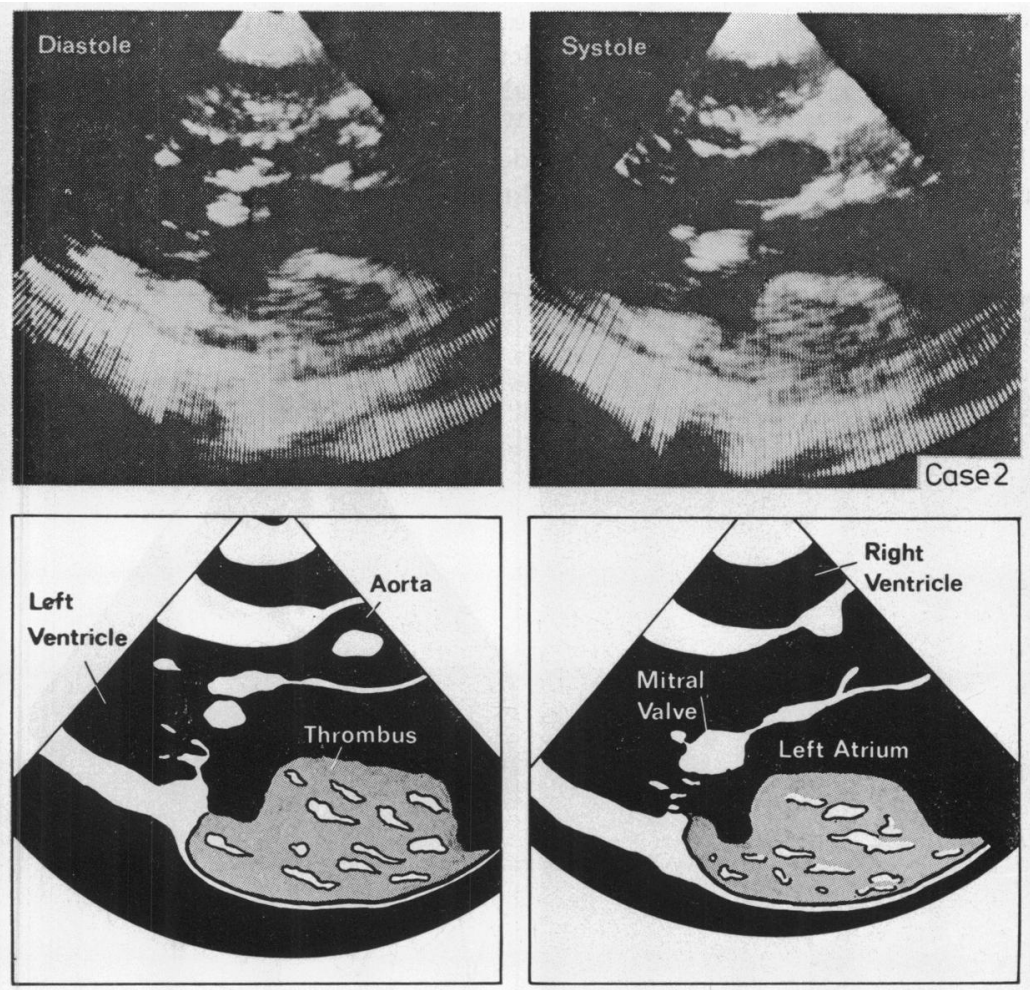

Fig. 3 Parasternal crosssections through the long axis of the heart and schematic diagrams (case 2). Large atrial mass in broad contact with the posterior left atrial wall, being immobile in diastole (left) and systole (right). The mass reaches the atrioventricular junction. The mitral and aortic leaflets are thickened because of mitral stenosis and aortic regurgitation. 

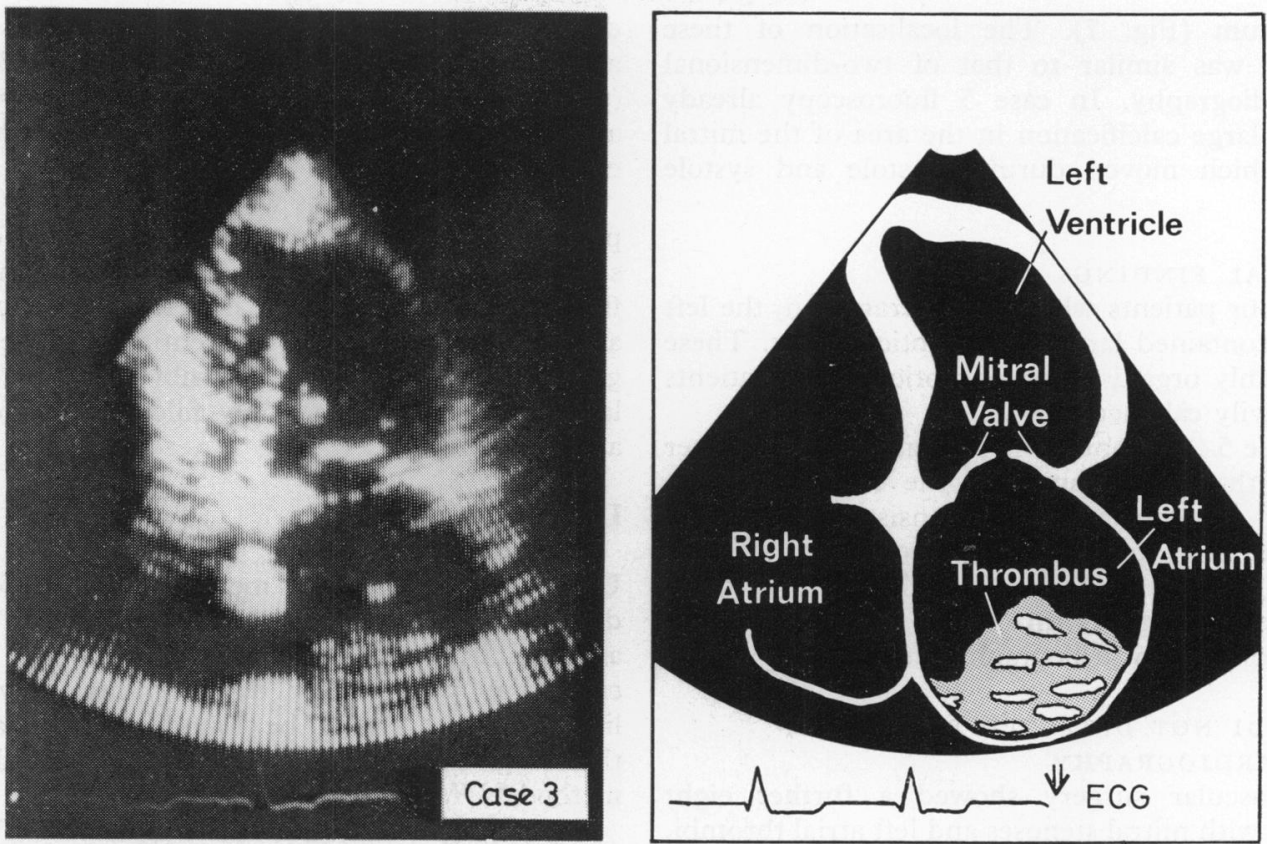

Fig. 4 Apex two-dimensional four chamber view (case 3). Huge echo mass covering lateral, septal, and upper parts of the left atrium in this cross-section. Different echo-density between the intracavitary mass and the atrial wall.

intracavitary masses has been clearly documented. Larger left ventricular thrombi in patients with coronary artery disease or congestive cardiomyopathy have been detected by this method. ${ }^{18} 19$ Moreover, in patients with prosthetic mitral valves postoperatively developed left atrial thrombi have also been clearly shown. ${ }^{20}$
This follow-up study of 111 patients with mitral stenosis provides further evidence of the ability to detect left atrial thrombi by cross-sectional echocardiography. Within 16 months five large atrial thrombi were demonstrated echocardiographically, and exactly localised before angiography and operation.
Fig. 5 Apex two-dimensional four chamber view (case 4). Thickened mitral valve (MV) leaflets. Large echo-dense mass (calcified thrombus) within the left atrium and fixed to the posterior mitral leaflet.
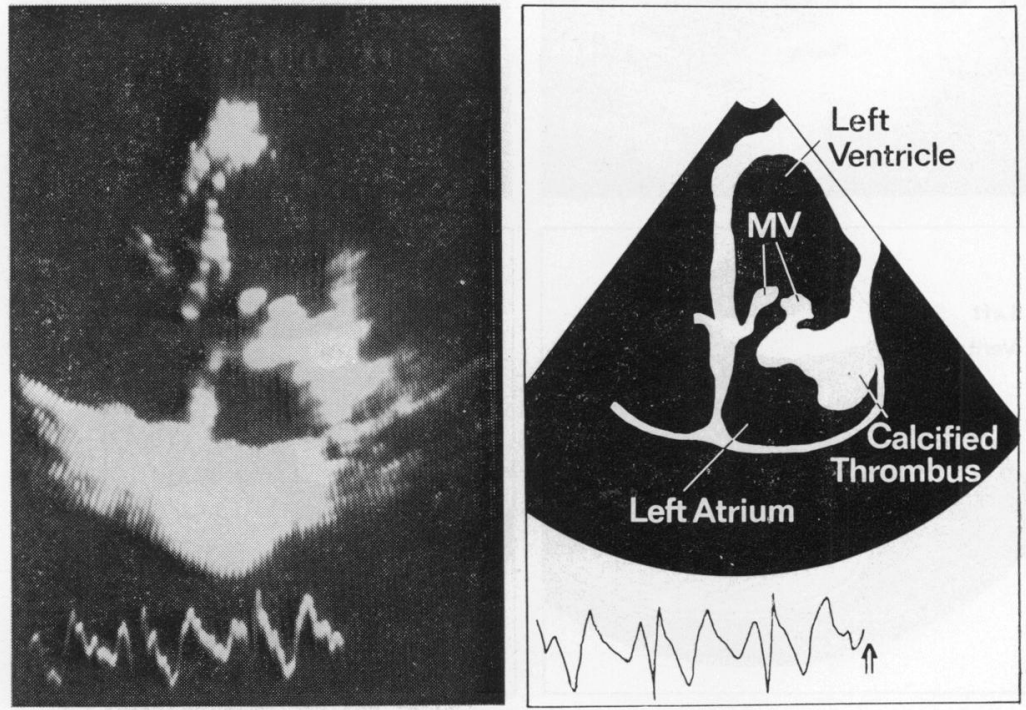

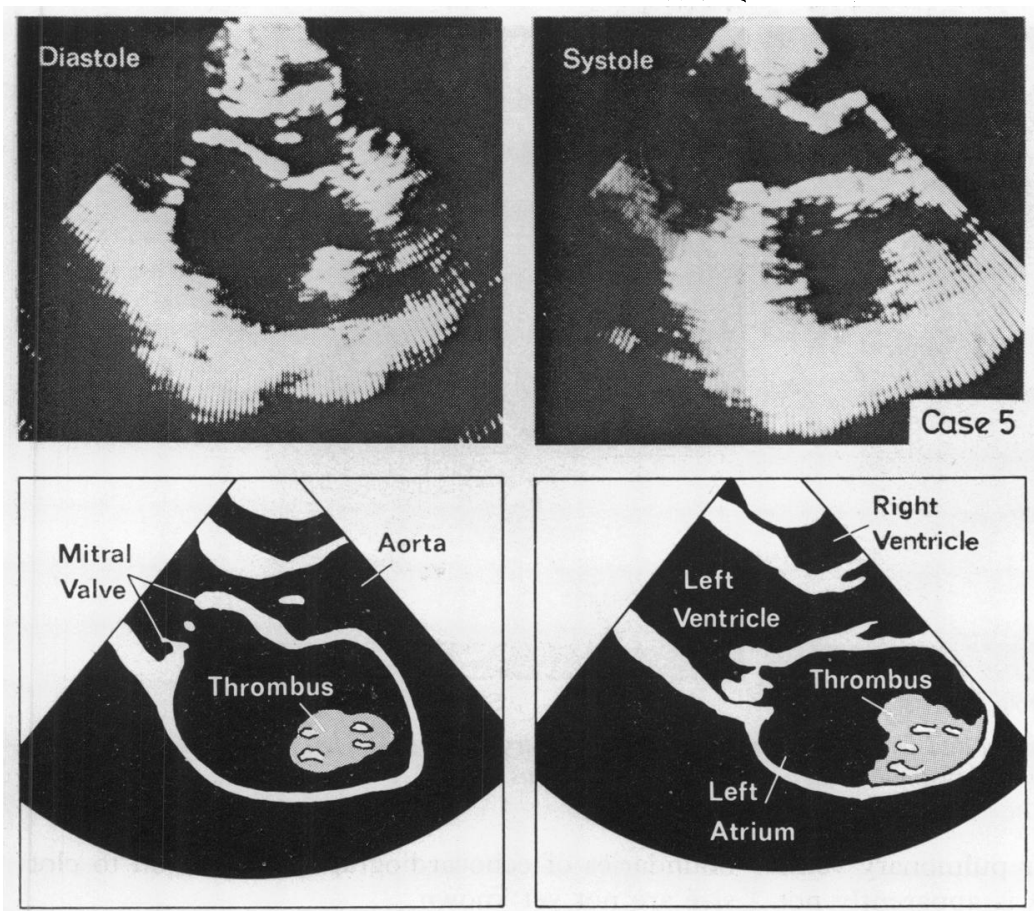

Fig. 6 Long axis cross-section of case 5 with mitral stenosis. Immobile echo mass deep within the left atrium, fixed to the superior atrial wall.
Using multiple parasternal and apical crosssections it is possible to look into more portions of the left atrial cavity. ${ }^{10}$ In particular the apex views allow an exact examination of the septal and lateral walls. ${ }^{9}$ The upper left atrial portion near the entrance of the inferior pulmonary veins is visible as well. In correlation with the morphological findings the extent and the size of the thrombi could be estimated in our study. Because of the spatial orientation and the better judgement of the dynamic movement of the left atrial masses, vague $M$-mode findings were clearly interpretable. In our experience two-dimensional echocardiography is therefore superior to the one-dimensional technique.

The diagnostic difficulties encountered in the use of $M$-mode echocardiography are well known in the presence of immobile thrombi which are in broad contact with the left atrial wall. ${ }^{21}$ Only masses in the neighbourhood of the mitral valve region are normally recorded by a routine $M$-mode sweep. But even then the strong continuous echoes of the anterior border of a left atrial mass can be misinterpreted as the true left atrial wall. False negative findings are also possible. Linear paralleling or fuzzy echoes are often observed within the left atrial cavity in spite of proper gain settings and can be mistaken for clots. The exact mechanism of the production of these artefacts is unclear. ${ }^{22}$
Using time-motion echocardiography, we obtained broad bands of echoes in front of the left posterior wall in three patients with mitral stenosis. These findings were consistent with the diagnosis of a left atrial thrombus. ${ }^{16} 1720$ The true extent of the thrombotic mass, covering the septal, lateral, and upper left atrial walls, could then be established with cross-sectional imaging. In one case with a calcified thrombus attached to the posterior mitral leaflet, $\mathrm{M}$-mode echocardiography suggested mitral valve ring calcification. This could be ruled out, however, using the other technique. One further patient with an echo-free left atrium during the M-mode sweep, showed a clot which was situated at the upper left atrial wall as demonstrated by cross-sectional ultrasound. This region of the atrium is normally not accessible to the single ultrasound beam.

Two-dimensional echocardiography eliminates some of the $M$-mode problems by recording larger portions of the left atrium, similarly to cineangiography. Despite this additional information, however, this technique constitutes an imperfect method for the detection of left atrial thrombi. During the follow-up period only onethird (four out of 12) of intraoperatively confirmed thrombi could be detected. These further eight thrombi were located within the left atrial appendage (seven cases) or adjacent to the upper wall 


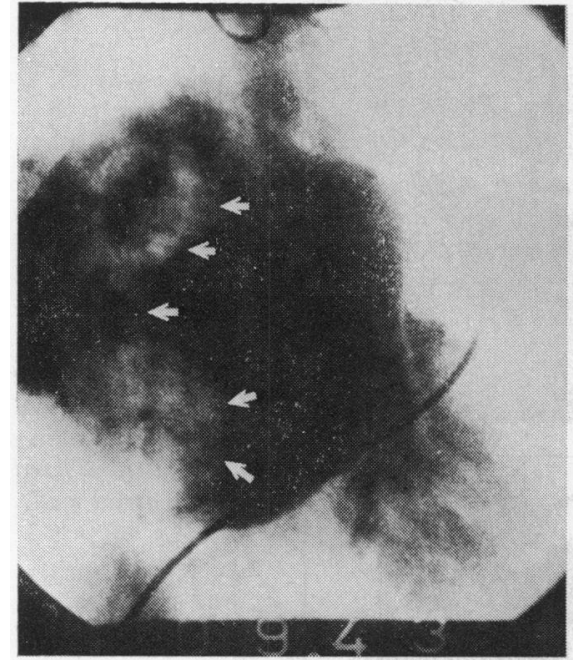

Diastole

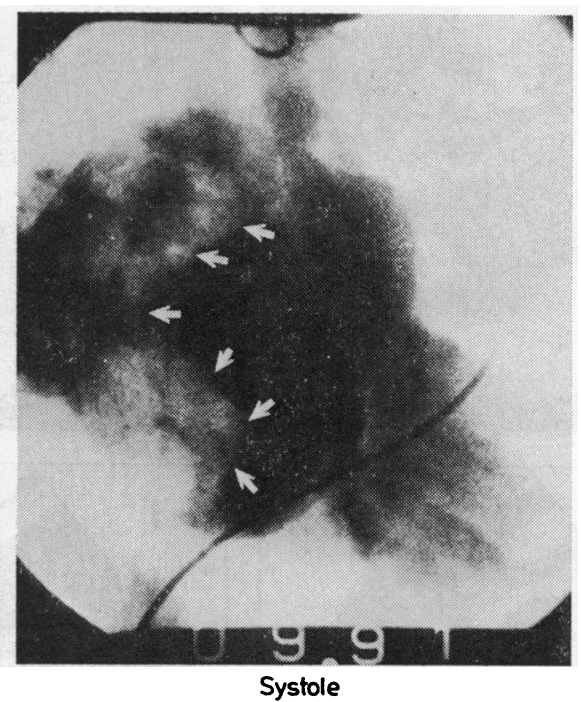

Fig. 7 Cineangiogram of the left atrium and left ventricle via pulmonary artery in diastole (left) and systole (right). Large immobile filling defects within the left atrium suggesting thrombus (case 2).

near the entrance of the superior pulmonary veins ( 1 case). A scan of these regions is apparently not possible by means of either the one- or the twodimensional technique. Furthermore, it must be emphasised that all the thrombi detected by ultrasound were relatively large. The sensitivity boundaries of echocardiography in relation to clot size are not yet known.

It is also uncertain what age a thrombus must reach in order to acquire a tissue density which is echocardiographically distinguishable from that of blood. A recent report on patients with prosthetic
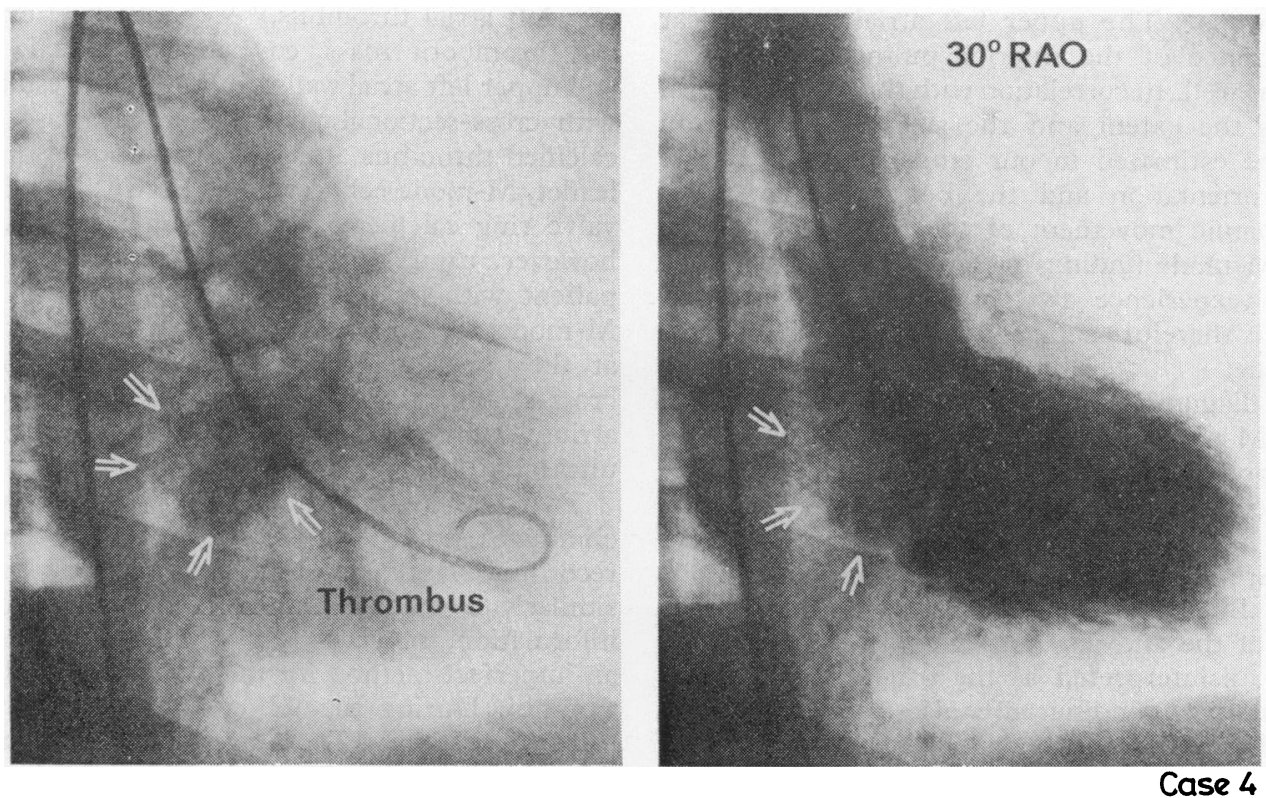

Fig. 8 Mobile calcified left atrial thrombus (arrows), already positive on fluoroscopy (left). Left ventricular cineangiogram in $30^{\circ} R A O$ projection (right): the calcified mass is attached to the posterior mitral leaflet. 


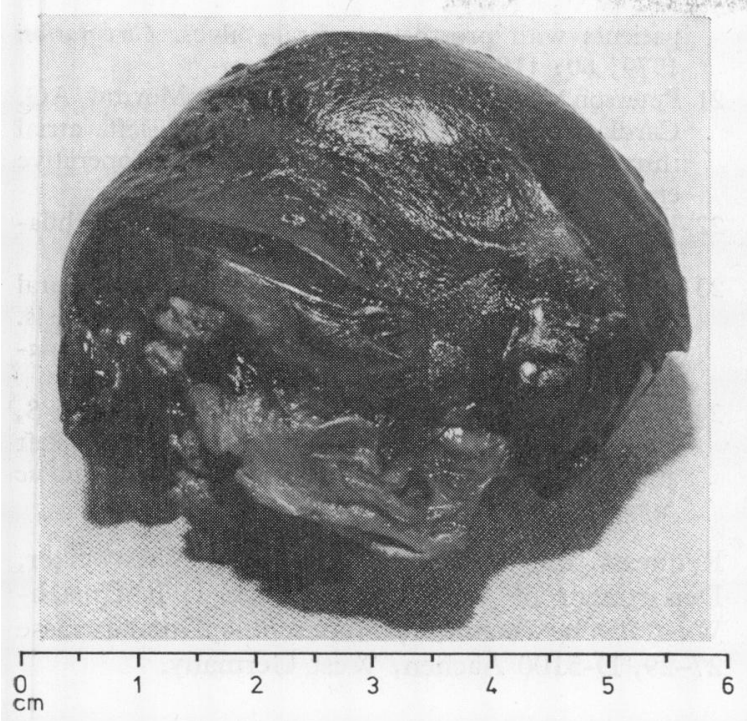

Fig. 9 Left atrial thrombus, removed at operation from case 5. This mass contained partly organised, partly fresh thrombotic material.

mitral valves maintains that thrombi may be imaged within days of their formation. ${ }^{20}$

In contrast to the ultrasound method, cineangiography also images the left atrial appendage, one of the main locations of left atrial thrombi. Clinicopathological studies indicate that mural thrombi in mitral stenosis are restricted to the left atrial appendage in approximately half of the cases. ${ }^{23}$ In keeping with previous reports, this invasive method was more successful and located two-thirds of thrombi subsequently found at operation. ${ }^{12-14}$

Nevertheless, the information provided by ultrasound can be most helpful in the management of patients. Warned of the presence of a thrombus, the surgeon can eliminate the rare potential risk of embolism during left heart catheterisation and during injection of dye into the left atrium. In five patients with positive echocardiographic findings, pulmonary artery injection of dye with followthrough to the left atrium was performed. In three of these five patients the thrombotic mass had also covered the interatrial septum, the point where the transseptal catheter normally passes into the left atrium.

Anticoagulation is urgently indicated after the non-invasive diagnosis of a left atrial thrombus. Two of our five patients had had previous embolic events, one being in sinus rhythm.

Finally, many surgeons still feel that closed commissurotomy is good treatment for selected patients with mitral stenosis provided the valve is pliable and not calcified. Patients with left atrial thrombi are unsuitable for closed commissurotomy. ${ }^{2124}$ Echocardiography and cineangiography are helpful in establishing this contraindication.

We conclude that two-dimensional and M-mode echocardiography are useful in the diagnosis and management of left atrial masses. Both procedures should be carried out in all patients with mitral stenosis before invasive diagnostic or therapeutic procedures are planned.

\section{References}

1 Kossowsky WA, Bleifer SB. Fatal cerebral embolus complicating transseptal left heart catheterization. Circulation 1965; 32: 811-3.

2 Ross J Jr. Considerations regarding the technique for transseptal left heart catheterization. Circulation 1966; 34: 391-9.

3 Samet P, Bernstein WH, Levine S. Transseptal left heart catheterization: an analysis of 390 studies. Dis Chest 1965; 48: 160-6.

4 Effert S, Domanig E. Diagnostik intraaurikulärer Tumoren und großer Thromben mit dem Ultraschall-Echoverfahren. Dtsch Med Wochenschr 1959; 84: 6-8.

5 Schattenberg TT. Echocardiographic diagnosis of left atrial myxoma. Mayo Clin Proc 1968; 43: 620-7.

6 Furuse A, Mizuno A, Inoue H, Furuta N, Saigusa M, Harada Y. Echocardiography and angiocardiography for detection of left atrial thrombus. Fpn Heart $\mathcal{F}$ 1976; 17: 163-71.

7 Tallury VK, DePasquale NP. Ultrasound cardiography in the diagnosis of left atrial thrombus. Chest 1971; 59: 501-3.

8 Kisslo J, Von Ramm OT, Thurstone FL. Dynamic cardiac imaging using a focused, phased-array ultrasound system. Am $\mathcal{F}$ Med 1977; 63: 61-8.

9 Silverman NH, Schiller NB. Apex echocardiography. A two-dimensional technique for evaluating congenital heart disease. Circulation 1978; 57: 503-11.

10 Tajik AJ, Seward JB, Hagler DJ, Mair DD, Lie JT. Two-dimensional real-time ultrasonic imaging of the heart and great vessels. Technique, image orientation, structure identification and validation. Mayo Clin Proc 1978; 53: 271-303.

11 Brockenbrough EC. Braunwald E. A new technic for left ventricular angiocardiography and transseptal left heart catheterization. Am $\mathcal{f}$ Cardiol 1960; 6: $1062-4$.

12 Lewis KB, Criley JM, Ross RS. Detection of left atrial thrombus by cineangiocardiography. $\mathrm{Am}$ Heart f 1965; 70: 612-9.

13 Ormond RS, Drake EH, Gale HH. Angiographic study of the left atrium in mitral stenosis. Radiology 1964; 83: 277-82.

14 Parker BM, Friedenberg MJ, Templeton AW, 
Burford TH. Preoperative angiocardiographic diagnosis of left atrial thrombi in mitral stenosis. $N$ Engl f Med 1965; 273: 136-40.

15 Soloff LA, Zatuchni J. The angiocardiographic diagnosis of left atrial thrombosis. Circulation 1956; 14: 25-32.

16 Graboys TB, Sloss LJ, Ockene IA. Echocardiographic diagnosis of left atrial thrombus-a case report. $\mathcal{F C U}$ 1977; 5: 284-5.

17 Spangler RD, Okin JT. Echocardiographic demonstration of a left atrial thrombus. Chest 1975; 67: 716-8.

18 De Maria AN, Bommer W, Neumann A. Left ventricular thrombi identified by cross-sectional echocardiography. Ann Intern Med 1979; 90: 14-8.

19 Ports TA, Cogan J, Schiller NB, Rappaport E. Echocardiography of left ventricular masses. Circulation 1978; 58: 528-36.

20 Mikell FL, Asinger RW, Rourke T, Hodges $M$, Sharma B, Francis GS. Two-dimensional echocardiographic demonstration of left atrial thrombi in patients with prosthetic mitral valves. Circulation 1979; 60: 1183-90.

21 Peterson LM, Fisher RD, Reis RL, Morrow AG. Cardiac operations in patients with left atrial thrombus, incidence and prevention of postoperative embolism. Ann Thorac Surg 1969; 8: 402-6.

22 Feigenbaum H. Echocardiography. 2nd ed. Philadelphia: Lea \& Febiger, 1976: 248-52.

23 Jordan RA, Scheifley CH, Edwards JE. Mural thrombosis and arterial embolism in mitral stenosis. A clinicopathologic study of fifty-one cases. Circulation 1951; 3: 363-7.

24 Verska JJ, Ludington LG, Walker WJ, Mundall S, Brewer LA. The occurrence and management of left atrial thrombi in mitral valve surgery. $f$ Cardiovasc Surg (Torino) 1974; 15: 516-21.

Requests for reprints to Dr Peter Schweizer, Department of Internal Medicine I, RheinischWestfälische Technische Hochschule, Goethestrasse 27-29, D-5100 Aachen, West Germany. 